\title{
A Study of Tibial Nerve in the Popliteal Fossa Along With Its Variations in Its Branching Pattern
}

\author{
W Benjamin ${ }^{\circledR 1}$, Raghavendra V Pisale ${ }^{\circledR 2}$, SA Premchand ${ }^{\circledR 3}$, Edward Indla ${ }^{\circledR 4}$, Seema Valsalan Ennazhiyil ${ }^{\oplus 1}$, VR Akshara ${ }^{\oplus 1}$, Lovely \\ S Livingston ${ }^{\circ 5}$ \\ ${ }^{1}$ Assistant Professor, Department of Anatomy, PK Das Institute of Medical Sciences, Palakkad, Kerala, India, ${ }^{2}$ Professor, Department of Anatomy, J.J. M. Medical College, \\ Davangere, Karnataka, India, ${ }^{3}$ Assistant Professor, Department of Anatomy, J.J.M. Medical College, Davangere, Karnataka, India, ${ }^{4}$ Tutor, Department of Anatomy, \\ Vijayanagar Institute of Medical Sciences, Bellary, Karnataka, India, ${ }^{5}$ Assistant Professor, Department of Community Medicine, PK Das Institute of Medical Sciences, \\ Palakkad, Kerala, India.
}

\section{Abstract}

Background: A detailed Knowledge of these variations in motor branching patterns will help the surgeons when certain procedures are done for calf reduction and also when selective neurectomy is required. It is also required by the anesthetists to give neurolytic blocks. Subjects and Methods: 40 formalin-fixed lower limbs of adult human cadavers were selected. The origin of the tibial nerve, variations in a branching pattern, number of muscular branches given was studied by dissection. The Level of origin of these nerves was taken to the apex of the head of the fibula (AHF). Results: In $70 \%$ of specimens the origin of the Tibial Nerve was $<12 \mathrm{~cm}$ and in $30 \%$ it was between $12-24 \mathrm{~cm}$ above the level of AHF. In $10 \%$ of cases, the sural nerve originated from the nerve to the medial head of gastrocnemius (MHG). In $82.5 \%$ of specimens, the MHG received one branch from the tibial nerve and in $17.5 \%$ it received two branches. The lateral head of Gastrocnemius (LHG) received one branch from the tibial nerve. In 10\%, there was a common branch for the LHG and the soleus muscle. $90 \%$ of specimens had one branch and $10 \%$ had two branches that supplied the soleus muscle. A single branch supplied the plantaris muscle. The popliteus muscle also received a single branch. Conclusion : The results in the study provide information that is required by the anatomists, surgeons, radiologists and anesthetists.

Keywords: Tibial Nerve, Variations in Branching pattern, Popliteal Fossa

Corresponding Author: SA Premchand, Assistant Professor, Department of Anatomy, J.J.M. Medical College, Davangere, Karnataka, India. E-mail: premchandsa@gmail.com

Received: 25 August 2020

Revised: 30 September 2020

Accepted: 08 October 2020

Published: 22 December 2020

\section{Introduction}

The tibial nerve (TN) is the largest component of the Sciatic nerve (SN), derived from the ventral branches of the fourth and fifth lumbar and first to third sacral ventral rami. In the popliteal fossa, the muscular branches arise between the two heads of gastrocnemius and supply gastrocnemius, plantaris, soleus and popliteus. ${ }^{[1]}$ The medial sural cutaneous nerve is derived from the tibial nerve in the popliteal fossa. ${ }^{[2]}$

TN injury occurs when there is a fracture of the lower end of the femur or proximal end of the tibia which is caused by high energy trauma during motor car accidents, fall from height and also by cut injuries in the popliteal fossa. ${ }^{[3]}$ TN injuries would lead to paralysis of all the muscles of the back of the leg and sole of the foot. The sensation is also lost on the sole of the foot which later leads to trophic ulcers. ${ }^{[4]}$
Knowledge about the TN in the popliteal fossa is important to give popliteal nerve block during surgeries. ${ }^{[5]}$ Tibial neurotomy ensures long term functional improvement of patients with spastic equinus foot. ${ }^{[6]}$ The safe and effective method for calf reduction is done by neurectomy of the nerve to medial gastrocnemius. ${ }^{[7]}$ For spasticity it is important to know the exact location and locational variations of the TN. ${ }^{[8]}$ The aim of the present study was to study the origin, relations, variations and branching pattern of TN in the popliteal fossa.

\section{Subjects and Methods}

The study was done by dissecting 40 formalin-fixed lower limbs of adult human cadavers. The TN was dissected and all the measurements were taken by keeping the apex of the head of the fibula (AHF) as a landmark. The measurements were taken using a measuring tape in centimeters. The branches of the tibial nerve were carefully dissected and studied 


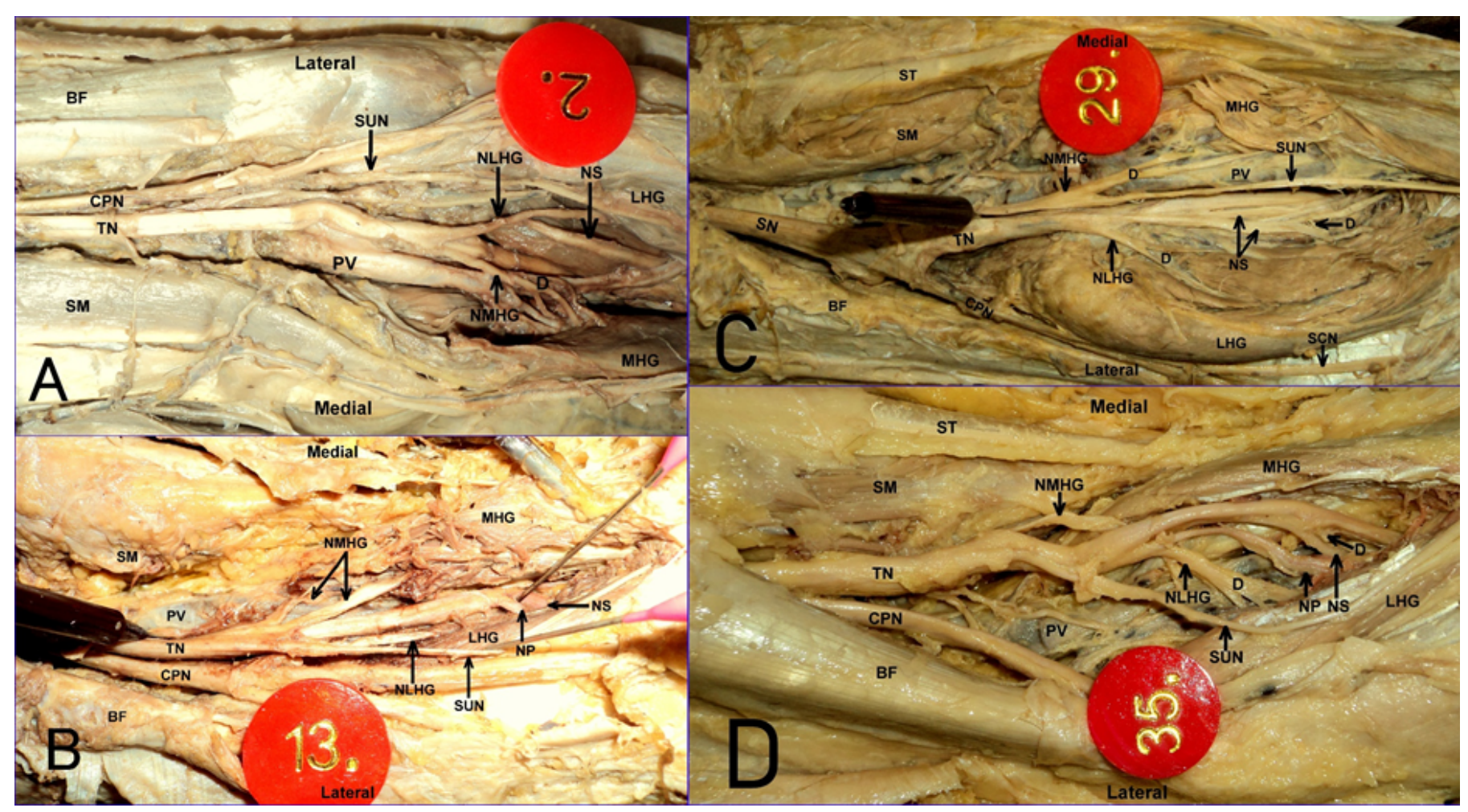

Figure 1: Photographs showing variations in the branching pattern of theTibial nerve in the Popliteal fossa. A) Nerve to Soleus (NS) originating from the Nerve to Lateral head of Gastrocnemius (NLHG). B) Two muscular branches supplying the Medial head of Gastrocnemius (MHG). C) Medial Sural cutaneous nerve (SUN) originating from nerve to Medial head of Gastrocnemius (NMHG). D) Nerve to Lateral head of Gastrocnemius (NLHG) showing three divisions. (BFBiceps Femoris, SM- Semimembranosus, ST-Semitendinosus, LHG-Lateral head of Gastrocnemius, SN-Sciatic Nerve, CPN-Common peroneal nerve, TN- Tibial nerve, NP-Nerve to Plantaris, D-Division, PV-Popliteal vein.

regarding the branching pattern, a number of branches given and divisions to Medial head of Gastrocnemius, Lateral head of Gastrocnemius, Soleus, Plantaris and Popliteus muscles. In the present study, all the values were measured from the first branch in the case when the muscle was supplied by more than one branch. The origin of the medial sural cutaneous nerve was also studied. The range, mean and standard deviation were calculated for the readings obtained.

\section{Results}

The distance of the origin of the nerves in relation to the AHF. [Table 1]

The mean site of origin of $\mathrm{TN}$ from the $\mathrm{SN}$ in relation to AHF was $10.42 \pm 2.71 \mathrm{~cm}$. The minimum distance of origin was $6 \mathrm{~cm}$ and the maximum distance of origin was $15.40 \mathrm{~cm}$ respectively. $70 \%$ of specimens $(n=28)$ showed that the site of origin was less than $12 \mathrm{~cm}$ above the level of AHF. $30 \%$ of specimens $(n=12)$ showed that the site of origin was between
$12 \mathrm{~cm}$ to $24 \mathrm{~cm}$ above the level of AHF.

The mean site of origin of the medial sural cutaneous nerve (SUN) in relation to the AHF was $7.56 \pm 1.76 \mathrm{~cm}$. The minimum distance of origin was $4.60 \mathrm{~cm}$ and the maximum distance of origin was $13 \mathrm{~cm}$ respectively. In $10 \%(\mathrm{n}=4)$ of cases, SUN originated from the NMHG instead of the TN and in $90 \%(n=36)$ of cases, the SUN originated from the TN.

The mean site of origin of NMHG in relation to the AHF was $7.03 \pm 0.99 \mathrm{~cm}$. The minimum distance of origin was $4.80 \mathrm{~cm}$ and the maximum distance of origin was $9.5 \mathrm{~cm}$ respectively. The mean site of origin of NLHG in relation to the AHF was $6.75 \pm 1.00 \mathrm{~cm}$. The minimum distance of origin was $4.30 \mathrm{~cm}$ and the maximum distance of origin was $9.20 \mathrm{~cm}$ respectively.

The mean site of origin of nerve to soleus muscle in relation to of apex of the head of the fibula was $6.03 \pm 0.97 \mathrm{~cm}$. The minimum distance of origin was $4.10 \mathrm{~cm}$ and the maximum distance of origin was $9.30 \mathrm{~cm}$ respectively. In $10 \%(\mathrm{n}=4)$ of cases, NS originated from the NLHG instead of the TN and in $90 \%(n=36)$ of cases, the NS originated from the TN. 
The mean site of origin of nerve to plantaris muscle in relation to the apex of the head of the fibula was $5.30 \pm 0.81 \mathrm{~cm}$. The minimum distance of origin was $3.50 \mathrm{~cm}$ and the maximum distance of origin was $7 \mathrm{~cm}$ respectively. The mean site of origin of nerve to popliteus muscle in relation to the apex of the head of the fibula was $3.89 \pm 0.48 \mathrm{~cm}$. The minimum distance of origin was $2.90 \mathrm{~cm}$ and the maximum distance of origin was $4.80 \mathrm{~cm}$ respectively.

In the present study all the values were measured from the first branch in the case when the muscle was supplied by more than one branch.

\section{Number of branches given by the nerve before it supplies the muscles. [Table 2]}

In $82.50 \%$ ( $\mathrm{n}=33$ ) of specimens, the MHG received one branch from the tibial nerve and in $17.50 \%(\mathrm{n}=7)$ of specimens it received two branches. $100 \%(n=40)$ of specimens had one branch which supplied the LHG. In $90.00 \%(n=36)$ of specimens the Soleus muscle received one branch and in $10 \%(n=4)$ it received two branches. In $10 \%(n=4)$ of cases, NS originated from the NLHG. All the specimens showed one branch which supplied the Plantaris muscle. The Popliteus muscle also received a single branch.

\section{Number of divisions given by the nerve before it supplies the muscles. [Table 3 ]}

In NMHG, $42.5 \%(\mathrm{n}=17)$ of specimens had two divisions and $57.5 \%(\mathrm{n}=23)$ of specimens showed no division. In NLHG $27.50 \%(\mathrm{n}=11)$ specimens showed two divisions, $2.50 \%$ ( $=1)$ of specimen showed three division and $70 \%(\mathrm{n}=28)$ of specimen showed no division.

In Nerve to soleus $32.50 \%(\mathrm{n}=13)$ specimens showed two divisions, $2.50 \%(\mathrm{n}=1)$ of specimen showed three division and $65 \%(\mathrm{n}=26)$ of specimen showed no division. The Nerve to plantaris and Popliteus showed no division.

\section{Discussion}

In the present study, the mean site of origin of the tibial nerve from the sciatic nerve in relation to the apex of the head of the fibula was $10.42 \pm 2.71 \mathrm{~cm}$. The minimum distance of origin was $6 \mathrm{~cm}$ and the maximum distance of origin was $15.40 \mathrm{~cm}$ respectively. A study done by Abdelghany AH et al, on 24 lower limbs showed that in $95.83 \%(\mathrm{n}=23)$ of specimens, the tibial nerve originated from the sciatic nerve at a range of 12 to $24 \mathrm{~cm}$ with a mean of $17.91 \pm 3.80 \mathrm{~cm}$ above the level of apex of ahead of the fibula. ${ }^{[9]}$

The study done by Abdelghany et al, ${ }^{[9]}$ tells us that the sural nerve arose from the tibial nerve in the popliteal fossa. In contrary to this, Liu et al, ${ }^{[7]}$ and Hwang et al, ${ }^{[10]}$ found that in $30 \%$ of the cases, the sural nerve originated from the nerve to the MHG muscle instead of the TN. In the present study we saw that in $10 \%(n=4)$ of cases, the sural nerve originated from the nerve to the MHG muscle instead of the TN. In the present study the mean site of origin of the sural nerve in relation to the apex of the head of a fibula was $7.56 \pm 1.76 \mathrm{~cm}$. The minimum distance of origin was $4.60 \mathrm{~cm}$ and the maximum distance of origin was $13 \mathrm{~cm}$ respectively.

The present study shows us that in $82.5 \%$ ( $\mathrm{n}=33)$ of specimens the MHG muscle received one branch from the $\mathrm{TN}$ and in $17.5 \%(n=7)$ of specimens it received two branches. The study done by Abdelghany et al, ${ }^{[9]}$ showed that the MHG received only one branch from the TN. Liu et al, ${ }^{[7]}$ found that in $70 \%$ of cases there was only one branch and in $30 \%$ of cases there were two branches seen supplying the MHG. This is similar to the observations in the present study. Jang et al, ${ }^{[11]}$ found only one motor branch to each head of the gastrocnemius. Hwang et al, ${ }^{[10]}$ found that $49 \%$ of cases had two branches for the medial head of the gastrocnemius. Kim et al, ${ }^{[12]}$ found one branch to the medial head in $75 \%$ of the cases, and two branches in $25 \%$ of cases. Sook et al, ${ }^{[13]}$ found one or two branches to the medial head of the gastrocnemius.

The study done by Abdelghany et al, ${ }^{[9]}$ showed that the nerve to the medial head of gastrocnemius muscle had an origin $5.21 \pm 0.38 \mathrm{~cm}$ above the level of AHF. In the present study the mean site of origin of nerve to the medial head of gastrocnemius in relation to the AHF was $7.03 \pm 0.99 \mathrm{~cm}$. The minimum distance of origin was $4.80 \mathrm{~cm}$ and the maximum distance of origin was $9.5 \mathrm{~cm}$ respectively. In the present study $42.5 \%(n=17)$ of specimens had two divisions from the nerve to the medial head of the gastrocnemius. In the present study all the values were measured from the first branch in the case when the muscle was supplied by more than one branch.

The LHG received only one branch from the TN $6.75 \pm 1.0$ $\mathrm{cm}$ above the level of AHF. The minimum distance of origin was $4.30 \mathrm{~cm}$ and the maximum distance of origin was $9.20 \mathrm{~cm}$ respectively. The study done by Abdelghany et al, ${ }^{[9]}$ showed that the TN supplied one branch to the lateral head alone or with the soleus muscle $4.41 \pm 0.74 \mathrm{~cm}$ above the level of apex of the head of the fibula. This is coinciding with the observations seen in the present study. In our present study, we observed that in $10 \%(\mathrm{n}=4)$ of specimens there was a common branch for the lateral head of the gastrocnemius and for the soleus muscle.

Jang et al, ${ }^{[11]}$ found only one motor branch to LHG muscle. Kim et al, ${ }^{[12]}$ detected only one branch supplying the lateral head. Sook et al, ${ }^{[13]}$ found up to four branches supplying the lateral head. Hwang et al, ${ }^{[10]}$ found one branch supplying the LHG. In the present study we found that in $30 \%(n=12)$ of specimens the nerve divided before it supplied the muscle. $27.50 \%(\mathrm{n}=11)$ specimens showed two divisions and $2.50 \%$ $(\mathrm{n}=1)$ of specimen showed three-division before it entered the muscle. In $10 \%(n=4)$ of specimens NS originated from the NLHG. 


\begin{tabular}{|c|c|c|c|c|}
\hline $\begin{array}{l}\text { Nerves in relation to } \\
\text { above the AHF }\end{array}$ & $\begin{array}{l}\text { Minimum Distance } \\
\text { (in } \mathrm{cm} \text { ) }\end{array}$ & $\begin{array}{l}\text { Maximum Distance (in } \\
\mathrm{cm} \text { ) }\end{array}$ & Mean (in cm) & $\begin{array}{l}\text { Standard Deviation (in } \\
\mathrm{cm} \text { ) }\end{array}$ \\
\hline Tibial Nerve & 6.00 & 15.40 & 10.42 & 2.71 \\
\hline $\begin{array}{l}\text { Medial sural cutaneous } \\
\text { nerve }\end{array}$ & 4.60 & 13.00 & 7.56 & 1.76 \\
\hline $\begin{array}{l}\text { Nerve to Medial head of } \\
\text { gastrocnemius }\end{array}$ & 4.80 & 9.50 & 7.03 & 0.99 \\
\hline $\begin{array}{l}\text { Nerve to Lateral head of } \\
\text { gastrocnemius }\end{array}$ & 4.30 & 9.20 & 6.75 & 1.00 \\
\hline Nerve to Soleus & 4.10 & 9.30 & 6.03 & 0.97 \\
\hline Nerve to Plantaris & 3.50 & 7.00 & 5.30 & 0.81 \\
\hline Nerve to Popliteus & 2.90 & 4.80 & 3.89 & 0.48 \\
\hline
\end{tabular}

Table 2: Number of branches given by the nerve before it supplies the muscles.

\begin{tabular}{lllll}
\hline Muscles & $\begin{array}{l}\text { One Branch } \\
\text { Specimen }\end{array}$ & Percentage \% & Two branches & Specimen \\
$\begin{array}{l}\text { Nerve to Medial head of } \\
\text { the gastrocnemius }\end{array}$ & 33 & 82.5 & 7 & Percentage \% \\
$\begin{array}{l}\text { Nerve to Lateral head of } \\
\text { the gastrocnemius }\end{array}$ & 40 & 100 & - & - \\
\hline $\begin{array}{l}\text { Nerve to Soleus } \\
\text { Nerve to Plantaris }\end{array}$ & 36 & 90 & 4 & 10 \\
\hline Nerve to Popliteus & 40 & 100 & - & - \\
\hline
\end{tabular}

Table 3: Number of divisions given by the nerve before it supplies the muscles.

\begin{tabular}{lllllll}
\hline Muscles & $\begin{array}{l}\text { No division } \\
\text { Specimen }\end{array}$ & Percentage \% & $\begin{array}{l}\text { Two Divisions } \\
\text { Specimen }\end{array}$ & Percentage \% & Specimen & Percentage \% \\
\hline $\begin{array}{l}\text { Nerve to Medial } \\
\text { head of the gas- } \\
\text { trocnemius }\end{array}$ & 23 & 57.5 & 17 & 42.5 & - & - \\
\hline $\begin{array}{l}\text { Nerve to Lateral } \\
\text { head of gastroc- } \\
\text { nemius }\end{array}$ & 28 & 70 & 11 & 27.5 & 1 & 2.5 \\
\hline $\begin{array}{l}\text { Nerve to Soleus } \\
\text { Nerve to Plan- } \\
\text { taris }\end{array}$ & 40 & 65 & 13 & 32.5 & 1 & 2.5 \\
\hline $\begin{array}{l}\text { Nerve to Popli- } \\
\text { teus }\end{array}$ & 100 & 10 & - & - & - & - \\
\hline
\end{tabular}

The study done by Abdelghany et al, ${ }^{[9]}$ showed that in $91.67 \%$, the tibial nerve gave a branch to the soleus at $6.84 \pm 0.91$ $\mathrm{cm}$ above the level of AHF and another branch $2.78 \pm 0.66 \mathrm{~cm}$ above the level of AHF. In the present study we found that $90 \%(n=36)$ of specimens had one branch which supplied the soleus muscle. $10 \%(\mathrm{n}=4)$ of specimens had two branches which supplied the muscle.
In the present study the mean site of origin of NS in relation to AHF was $6.03 \pm 0.97 \mathrm{~cm}$. The minimum distance of origin was $4.10 \mathrm{~cm}$ and the maximum distance of origin was $9.30 \mathrm{~cm}$ respectively. In the present study all the values were measured from the first branch in the case when the muscle was supplied by more than one branch. 
Sook et al, ${ }^{[13]}$ and Deltombe et al, ${ }^{[14]}$ found one branch to the soleus muscle. Sekiya et al, ${ }^{[15]}$ mentioned that the soleus muscle was supplied by two branches from the TN. Decq et al, ${ }^{[16]}$ showed that the spasticity of the soleus muscle was mainly responsible for spastic equinus foot in $75 \%$ of cases, and the gastrocnemius was involved in only $12.5 \%$ of cases. Treatment of the spastic equinovarus foot is multimodal and it includes physical therapy, peripheral selective neurotomy and tendon transfer. The selective fascicular neurotomy consists of a partial section of the motor branches to the muscles presenting excessive spasticity. ${ }^{[17,18]}$ In a study done by Roujeau et al, ${ }^{[19]}$ fascicular resection of the NS alone was sufficient to reduce spastic equinus foot.

Tibial neurotomy led to the disappearance of spasticity with the improvement of the gait in all patients. ${ }^{[20,21]} \mathrm{Mu}$ et al, ${ }^{[22]}$ treated 52 cases with neurotomy and the spastic gait was improved. The study done by Wang et al, ${ }^{[23]}$ found that $85 \%$ of the cases of equinus foot have improved after selective neurotomy. A selective tibial nerve block with anesthetics stops spasticity for a few hours, allowing evaluation of the resulting functional improvement. It helps to predict the improvement that could be expected from the permanent treatment. So Selective tibial nerve block is tried before considering the permanent treatment methods like selective neurotomy. ${ }^{[14,24]}$ The study done by Abdelghany et al, ${ }^{[9]}$ showed that in $8.33 \%$ of cases had a common branch for the soleus and the lateral head of gastrocnemius that divided into two branches to the upper border of the muscle. This is similar to the observations seen in the present study.

Hwang et al, ${ }^{[10]}$ described that one nerve branch supplied the soleus muscle and in $30 \%$ of the cases the nerve originated from the nerve innervating the lateral head of gastrocnemius muscle. This also correlates with the current study. In the present study, we observed that in $10 \%(n=4)$ of specimens the nerve to soleus muscle originated from the nerve to lateral head of gastrocnemius muscle. In the study done by Abdelghany et $\mathrm{al},{ }^{[9]}$ the upper branch to the soleus muscle was later divided into three branches to the upper border of the muscle. The lower branch is also divided into three branches to supply the deep surface of the muscle. In the present study done on 40 specimens, $35 \%(\mathrm{n}=14)$ of the branches showed divisions. $32.5 \%(\mathrm{n}=13)$ branches showed two divisions. $2.5 \%(n=1)$ showed three divisions. Out of four specimens that showed two branches, two specimens showed that the division was from the upper branch and two specimens showed that the division was from the lower branch supplying the muscle.

\section{Nerve to Plantaris Muscle}

In the present study we found that all the specimens had one branch which supplied the plantaris muscle. The mean site of origin of nerve to plantaris muscle in relation to the apex of the head of the fibula was $5.30 \pm 0.81 \mathrm{~cm}$. The minimum distance of origin was $3.50 \mathrm{~cm}$ and the maximum distance of origin was $7 \mathrm{~cm}$ respectively. A study done by Abdelghany et al, ${ }^{[9]}$ showed that the plantaris muscle was supplied by a branch of the tibial nerve on its medial border and the nerve originated around $5.33 \pm 0.71 \mathrm{~cm}$ from the apex of the head of the fibula. This is coinciding with the observations seen in the present study.

\section{Nerve to Popliteus Muscle}

In the present study we found that all the specimens had one branch which supplied the popliteus muscle. The mean site of origin of nerve to popliteus muscle in relation to the apex of the head of the fibula was $3.89 \pm 0.48 \mathrm{~cm}$. The minimum distance of origin was $2.90 \mathrm{~cm}$ and the maximum distance of origin was $4.80 \mathrm{~cm}$ respectively. A study done by Abdelghany et $\mathrm{al}^{\left[{ }^{[9]}\right.}$ showed that the popliteus muscle received a branch from the tibial nerve $3.62 \pm 0.58 \mathrm{~cm}$ above the level of apex of the head of the fibula. This branch curved around the lower border of the muscle to its deep surface. This is similar to the observations seen in the present study. In the present study all the values were measured from the first branch in the case when the muscle was supplied by more than one branch.

\section{Conclusion}

The present study on the South Indian population provides considerable information on the branches given by the tibial nerve in the posterior compartment of the leg. The variation in the branching pattern of the tibial nerve in the posterior compartment of the leg was at par with the studies done in other regions of the world. Detailed knowledge of these variations and motor branching patterns may help the surgeons operating around this area and also in certain procedures done for calf reduction where selective neurectomy is required and also to treat Spastic equinovarus foot. It is also required for anesthetists for inducing neurolytic blocks.

\section{References}

1. Standring S, Borley NR, Collins P, Crossman AR, Gatzoulis MA, Healy JC. Gray's Anatomy: The Anatomical Basis of Clinical Practice. 40th ed.. London: Elsevier Churchill livingstone; 2008. p. 1421-27.

2. Moore KL, Dalley AF, Agur M. Clinically oriented anatomy. 6th ed.. Lippincott Williams and Wilkins; 2009. p. 584-7.

3. Noaman H, Rayegani S. Surgical treatment of peripheral nerve injury: Basic Principles of Peripheral Nerve Disorders; 2012. p. 115.

4. RS S. Clinical anatomy by regions. 9th ed. Lippincott Williams and Wilkins; 2012. p. 479.

5. Saleh HAM, El-Fork MM, Ga. Anatomical variation of sciatic nerve division in the popliteal fossa and its implication on popliteal nerve blockade. Folia Morphol. 2009;68(4):256-259. 
6. Buffenoir K, Roujeau T, Lapierre F, Menei P, MenegalliBoggelli D, Mertens P, et al. Spastic Equinus Foot: Multicenter Study of the Long-term Results of Tibial Neurotomy. Neurosurg. 2004;55(5):1130-1137. Available from: https://dx.doi. org/10.1227/01.neu.0000140840.59586.cf.

7. Liu DL, Li XI, Shan L, Li Q, Yuan JL, Yuan Q. The anatomic study and clinical observation of the neurectomy of the nerve to the medial gastrocnemius muscle for calf reduction. Zhonghua Zheng Xing Wai Ke Za Zhi. 2007;23(2):125-127.

8. Yoo WK, Chung IH, Park C. Anatomical motor point localization for the treatment of gastrocnemius muscle spasticity. Yonsei Med J. 2002;43(5):627-630. Available from: https: //doi.org/10.3349/ymj.2002.43.5.627.

9. Abdelghany AH. Anatomical study of the tibial nerve. Bull Alex Fac Med. 2009;45(3):759-70.

10. Hwang K, Kim YJ, Chung IH, Won HS, Tanaka S, Lee S. Innervation of calf muscles in relation to calf reduction. Ann Plast Surg. 2003;50:517-522. Available from: https://doi.org/ 10.1097/01.sap.0000044364.71359.bc.

11. Jang SH, Ahn SH, Park SM, Kim SH, Lee KH, Lee ZI. Alcohol neurolysis of tibial nerve motor branches to the gastrocnemius muscle to treat ankle spasticity in patients with hemiplegic stroke. Arch Phys Med Rehabil. 2004;85(3):506508. Available from: https://doi.org/10.1016/s0003-9993(03) 00468-4.

12. Kim SC, Kang MH, Ock JJ. Calf-Contouring Surgery of Gastrocnemius Hypertrophy: Selective Neurectomy of the Sural Nerve. Aesthetic Plastic Surg. 2008;32(6):889-893. Available from: https://dx.doi.org/10.1007/s00266-007-91075.

13. Kim HS, Hwang JH, Lee PKW, Kwon JY, Oh-Park MY, Kim JM, et al. Localization of the Motor Nerve Branches and Motor Points of the Triceps Surae Muscles in Korean Cadavers. Am J Phys Med Rehabil. 2002;81(10):765-769. Available from: https://dx.doi.org/10.1097/00002060-200210000-00008.

14. Deltombe T, Wispelaere JFD, Gustin T, Jamart J, Hanson P. Selective blocks of the motor nerve branches to the soleus and tibialis posterior muscles in the management of the spastic equinovarus foot. Arch Phys Med Rehab. 2004;85(1):54 58. Available from: https://dx.doi.org/10.1016/s0003-9993(03) 00405-2.

15. Sekiya S, Kumaki K, Yamada TK, Horiguchi M. Nerve Supply to the Accessory Soleus Muscle. Acta Anat. 1994;149(2):121127. Available from: https://doi.org/10.1159/000147566.

16. Decq P, Cuny E, Filipetti P, Kéravel Y. Role of soleus muscle in spastic equines foot. Lancet. 1998;352(9122):118. Available from: https://dx.doi.org/10.1016/s0140-6736(98)85025-3.
17. Decq P. Peripheral neurotomies for the treatment of focal spasticity of the limbs. Neurochirurgie. 2003;49:293-305.

18. Feve A, Decq P, Filipetti P, Verroust J, Harf A, N'Guyen JP, et al. Physiological effects of selective tibial neurotomy on lower limb spasticity. J Neurol Neurosurg Psychiatry. 1997;63(5):575-578. Available from: https://dx.doi.org/10. 1136/jnnp.63.5.575.

19. Roujeau T, Lefaucheur J, Slavov V, Gherardi R, Decq P. Long term course of the $\mathrm{H}$ reflex after selective tibial neurotomy. J Neurol Neurosurg Psychiatry. 2003;74(7):913-917. Available from: https://dx.doi.org/10.1136/jnnp.74.7.913.

20. Deltombe T, Detrembleur C, Hanson P, Gustin T. Selective Tibial Neurotomy in the Treatment of Spastic Equinovarus Foot. Am J Phys Med Rehabil. 2006;85(1):8288. Available from: https://dx.doi.org/10.1097/01.phm. 0000193506.70371.cf.

21. Decq P, Cuny E, Filipetti P, Feve A, Keravel Y. Peripheral neurotomy in the treatment of spasticity; indications, techniques and results in the lower limbs. Neurochirurgie. 1998;44(3):175-82.

22. Mu XH, Xu L, Xu SG, Cao X, Zhang P, Zheng CY, et al. Treatment of equinovarus caused by cerebral palsy with neurotomy of muscular branch of tibial nerve. Zhongguo $\mathrm{Gu}$ Shang. 2009;22(1):31-32.

23. Wang SJ, Chen GQ, Xiu B, Zuo HC. Neurotomy of the tibial nerve for treatment of the talipes equinovarus. Zhonghua Wai Ke Za Zhi. 2005;43(9):605-607.

24. Deltombe T, Jamart J, Hanson P, Gustin T. Soleus H reflex and motor unit number estimation after tibial nerve block and neurotomy in patients with spastic equinus foot. Neurophysiol Clin. 2008;38(4):227-233. Available from: https://doi.org/10. 1016/j.neucli.2008.03.003.

Copyright: (C) the author(s), 2020. It is an open-access article distributed under the terms of the Creative Commons Attribution License (CC BY 4.0), which permits authors to retain ownership of the copyright for their content, and allow anyone to download, reuse, reprint, modify, distribute and/or copy the content as long as the original authors and source are cited.

How to cite this article: Benjamin W, Pisale RV, Premchand SA, Indla E, Ennazhiyil SV, Akshara VR, Livingston LS. A Study of Tibial Nerve in the Popliteal Fossa Along With Its Variations in Its Branching Pattern. Acad. Anat. Int. 2020;6(2):29-34.

DOI: dx.doi.org/10.21276/aanat.2020.6.2.6

Source of Support: Nil, Conflict of Interest: None declared. 